\title{
Sarcoidosis 2001
}

\author{
D Geraint James
}

relentless progressive fibrosis. Corticosteroids relieve symptoms, suppress the formation of granulomas (including Kveim-Siltzbach granulomas), and normalise both levels of SACE and the uptake of gallium. A synthesis of clinical features, radiology, histology, biochemical changes, and immunological abnormalities helps to distinguish it from nonspecific local sarcoid-tissue reactions.

Genetic and other molecular probes may help to define a sarcoidosis terrain or diathesis and what antigens have a causative role in that susceptible soil.

\section{Immunology}

Granulomas form by a stepwise series of events, starting when $\mathrm{T}$ helper cells recognise protein peptides presented to them by antigen presenting cells bearing histocompatibility class II molecules. Immunological reactivity or inflammation attract monocyte macrophages which fuse to form multinucleated giant cells and onwards to epithelioid cells. Granuloma formation is aided by a cavalcade of chemotactic factors; Th 1 cells induce interleukin (IL)-2, interferon gamma, and tumour necrosis factor (TNF) with the help of IL-12 and costimulator B7. The resulting exuberant granuloma formation is associated with active cell mediated hypersensitivity and tissue destruction. This framework is also remodelled by chemokines, adhesion molecules, matrix receptors of the integrin family, costimulators B7 and CD28, IL-12, and RANTES (regulated on activation normal $\mathrm{T}$ cells as secreted).

Bronchoalveolar fluid (BALF) reveals this macrophage class II-CD4Th1 cell synergy with its awesome cytokine cascade. Angiotensin converting enzyme is generated within mature epithelioid granulomas; monocyte chemoattractant protein-1 is detected in macrophages peripheral to the granuloma but not within it. Antigen presenting cells and monocyte chemoattractant protein-1 should not be confused for they act at different stages of granuloma formation. Both reflect early sarcoid activity and are likely to be undetected at the late fibrotic stage. Interferon-inducible protein-10 correlates with activated Th1 cells in BALF. ${ }^{2-8}$

Anergy is an exquisite form of immune apathy due to cytokine dysregulation and signal transduction. With CD28 mediated costimulator there is active $\mathrm{T}$ cell proliferation; without it there is ignorance, apathy, and anergy. CD28 and B7 are transmembrane glycoprotein signals on helper $\mathrm{T}$ cells and antigen presenting cells respectively. The signals induce the $\mathrm{T}$ cell to produce IL-2, which in turn activates the $\mathrm{T}$ cell to proliferate and interact with B cells and cytoxic $\mathrm{T}$ cells. In due course this costimulation must end and the activated helper $\mathrm{T}$ cells are brought under control. This is done by cytotoxic $\mathrm{T}$ lymphocyte antigen 4 gene

Submitted 17 April 2000 Accepted 22 August 2000

Royal Free Hospital, Correspondence to: Dr James mode of onset. An acute onset usually heralds a self limited course of spontaneous resolution, whereas an insidious onset may be followed by 
Table 1 The chemicals and cytokines which promote and inhibit the road from granuloma to fibrosis (after Elliott, 1999) ${ }^{13}$

\begin{tabular}{ll}
\hline Promoted by & Inhibited by \\
\hline Th2 cytokines & Th1 cytokines \\
Interleukin-1 & Interferon gamma \\
Interleukin-4 & Interleukin-12 \\
RANTES & Corticosteroids \\
Type 1 procollagen & Prostaglandin E \\
Type 1 collagen & Perfenidone \\
Fibronectin & Pentoxyfylline \\
Factors & Thalidomide \\
Tumour necrosis & Bosentan \\
Transforming growth- $\beta$ & Halofuginone \\
Platelet derived growth & Factor antibody \\
Endothelin-1 & Transforming growth \\
& Tumour necrosis \\
& Infliximab \\
& Entanercept \\
\hline
\end{tabular}

(CTLA-4) a regulatory molecule on the surface of activated T helper cells. ${ }^{9} 10$

Apoptosis is another mechanism to switch off granulomatous inflammation, achieved via Fas antigen (Fas) and Fas ligand (Fas L). Fas, a cell surface protein that mediates apoptosis is a member of the TNF receptor family. Fas $L$ is expressed in activated $\mathrm{T}$ lymphocytes. The Fas/Fas L combination mediates apoptosis of Fas bearing cells, eliminating unwanted inflammatory cells during repair after injury. In this way, apoptosis may be regarded as an useful mechanism resolving granulomatous inflammation and preventing postinflammatory scarring and fibrosis. ${ }^{11}$

Granulomatous inflammation is usually self limiting with spontaneous resolution. It remains a mystery why some patients with sarcoidosis behave in this way whereas in others there is uncontrolled progress to fibrosis. Could one aspect of the puzzle be homoeostasis?

\section{Homoeostasis}

Armstrong et al have demonstrated an important inter-relationship between $\mathrm{TNF}-\alpha$ and TNF soluble receptors in pulmonary sarcoidosis. ${ }^{12}$ Alveolar macrophages were cultured in the presence and absence of lipopolysaccharide. There was significant more immunoreactive TNF- $\alpha$ in the BALF than in controls. TNF- $\alpha$ bioactivity was inhibited by increased soluble TNF receptors (TNF-R), particularly in early stage 1 intrathoracic involvement, suggesting a homoeostatic mechanism protecting the lung from excessive TNF production. Indeed, this mechanism may provide one explanation which may prevent subsequent on-going pulmonary fibrosis.

The CD4:CD8 ratio and TNF- $\alpha$ levels in induced sputum correlate with those in BALF and also parallels changes with steroid treatment. ${ }^{13}$ The raised CD4:CD8 ratio and increased $\mathrm{TNF}-\alpha$ levels in induced sputum in pulmonary sarcoidosis falls towards normal after six months' treatment with oral prednisone. This should prove to be a popular noninvasive method of assessing activity and a monitor of progress with treatment.

The road from granuloma to fibrosis

The most sinister clinical complications or sarcoidosis are the irreversible fibrosis causing glaucoma, cataract, and blindness; nephrocalcinosis; crippling pulmonary failure; hydrocephalus, lupus pernio, and myocardial damage. Indeed, but for fibrosis, sarcoidosis would be clinically insignificant. It is important to explore every antifibrotic avenue of prevention as early as possible in the disorder. The road from granuloma to fibrosis may be accelerated or inhibited by various chemicals and cytokines, and these mechanisms have been expertly discussed in a recent review (table 1). ${ }^{14}$ Pirfenidone ameliorates bleomycin fibrosis, inhibits transforming growth factor, and blocks profibrotic cytokines. ${ }^{15}$

\section{Markers of activity}

The need for steroid therapy depends whether sarcoidosis is active. Clinical features of activity are erythema nodosum, uveitis, rashes, polyarthralgia, dactylitis, myopathy, neuropathy, lymphadenopathy, parotid and lacrimal gland enlargement, red scars, and cardiac arrhythmia.

It is helpful to complement these clinical features with new techniques. All available data are used to assess activity and serial measurements monitor progress of the disease with treatment (table 2).

Table 2 Markers of activity of sarcoidosis

\begin{tabular}{lll}
\hline Technique & Abnormality & Reflecting \\
\hline $\begin{array}{l}\text { Serum angiotensin converting enzyme } \\
\text { Monocyte chemoattractant protein }\end{array}$ & Raised & Epithelioid granulomas \\
Interferon inducible protein & Raised & Macrophage activity \\
Radioactive Ga ${ }^{67}$ and octreotide & Raised & Activated lymphocytes, granulomas, and BAL \\
Bronchoalveolar lavage (BAL) & Uptake in granulomas & Activated macrophages \\
& Increased CD4:CD8 ratio over 3.5 & Sarcoid alveolitis activity \\
& RANTES & \\
Increased TGF- $\beta$ & \\
Calcium metabolism & Imbalance IL-Ira:IL-1 $\beta$ & Calcitriol sensitivity by alveolar macrophages \\
Kappa and lambda chain immunoglobulins & Hypercalcaemia & \\
Tuberculin skin test & Raised & B cell overactivity \\
& Negative & Cutneous cytokine anergy \\
Kveim-Siltzbach skin test & Interleukin-12 neutralised \\
Lung infection spirometry & Positive & Specific for sarcoidosis \\
& Interaction of CD4T cells and macrophages leading to granuloma \\
Tc-DTPA lung scan & Impairment & Granuloma load \\
Fluorescein angiography & Inflammation- fibrosis \\
ECG and 24 hour tape & Impaired clearance & Epithelial cell permeability due to inflammation \\
Magnetic resonance & Retinal vasculitis with leakage & Indication for steroid therapy and/or laser to overcome leakage \\
& Cardiac arrhythmia & Myocardial sarcoidosis \\
& Abnormal & Mediastinal adenopathy
\end{tabular}


Table 3 Present conventional treatments

\begin{tabular}{|c|c|c|}
\hline Drug & Routes & Remarks \\
\hline Corticosteroid & $\begin{array}{l}\text { Oral } \\
\text { Eye drops } \\
\text { Ointment } \\
\text { Intravenous } \\
\text { Topical }\end{array}$ & $\begin{array}{l}\text { The first line of treatment. } \\
\text { Dose may be reduced when given in conjunction with other effective drugs } \\
\text { Intravenous pulses for neurosarcoidosis }\end{array}$ \\
\hline Non-steroidal anti-inflammatory & $\begin{array}{l}\text { Oral } \\
\text { Ointment } \\
\text { Intravenous }\end{array}$ & $\begin{array}{l}\text { Helpful in acute exudative stage such as erythema nodosum, polyarthralgia, } \\
\text { and acute iritis }\end{array}$ \\
\hline Methotrexate & Oral once weekly for 9 months & $\begin{array}{l}\text { Helpful in controlling chronic skin lesions. May improve vital capacity in } \\
\text { chronic pulmonary sarcoidosis }\end{array}$ \\
\hline Hydroxychloroquine & Oral thrice weekly for 9 months & Helpful for chronic fibrotic lesions of skin and lung \\
\hline $\begin{array}{l}\text { Immunosuppression } \\
\text { Azathioprine } \\
\text { Cyclophosphamide }\end{array}$ & Oral accompanying corticosteroid & Steroid sparing effect making it possible to halve the dose of corticosteroid \\
\hline $\begin{array}{l}\text { Chlorambucil } \\
\text { Calcium chelating } \\
\text { Effervescent phosphate } \\
\text { Sodium cellulose phosphate }\end{array}$ & Oral until abnormal calcium corrected & $\begin{array}{l}\text { Chelate calcium in the gut and prevent its absorption } \\
\text { Best combined with corticosteroid }\end{array}$ \\
\hline $\begin{array}{l}\text { Potassium } \\
\text { p-aminobenzoate }\end{array}$ & Oral for 9 months & Softens fibrotic skin lesions and keloids \\
\hline
\end{tabular}

\section{Treatment}

Conventional treatment of the past comprised steroids followed, if necessary, by methotrexate or hydroxychloroquine (table 3 ). But this often proved insufficient, and the combined use of all three drugs came into use. This is to be encouraged so that different influences-antiinflammatory and antifibrotic-are brought into play. Early treatment is the key to the prevention of sinister fibrosis; and hopefully it will make transplantation less necessary.

We must also look beyond our present drugs for additional cytokine therapy for they and their antagonists are the antibiotics and magic bullets of the future (table 4). Nature has herself curbed the overactivity of TNF by producing neutralising TNF-R. It is suggested that this homoeostasis is responsible for the more benign course of early rather than late sarcoidosis. Other TNF blockers include thalidomide and pentoxyfyline. Infliximab is a humanmouse chimeric anti-TNF- $\alpha$ IgG antibody which has been successful in the management of rheumatoid arthritis, Crohn's disease, and psoriasis. Etanercept is a fusion protein made up of two recombinant p75 TNF receptors fused with the Fc portion of the human $\mathrm{IgG}_{1}$. Infliximab is an antibody against TNF- $\alpha$ whereas etanercept is a receptor for TNF; the former is a human-mouse chimeric product whereas the latter is a fully human protein.

\section{Aetiology}

The causes of sarcoidosis comprise two interwoven factors, namely the genetic background and the environmental operative target.

The genetic background is often referred to under the terms terrain, diathesis, and constitution. Erythema nodosum is seen most frequently in Irish women, Puerto Ricans reaching New York, and Martiniques migrating to Paris. Sarcoidosis is more common in Afro-Americans and in the West Indies. It is common in the Japanese but infrequent in Chinese, Greeks, and Cypriots. A recessive mode of inheritance is evident in familial sarcoidosis. There is some correlation between genetic predisposition and whether the course of the disease carries a good or poorer prognosis (table 5 ). ${ }^{16}$

Takemoto et al have noted an association between angiotensin II receptor gene polymorphism and SACE activity in patients with sarcoidosis. ${ }^{17}$

It is equally important to investigate triggers which may set in motion the disorder in predisposed individuals. Many different antigens have been suspected including bacteria, fungi, viruses, and chemicals (table 6). ${ }^{5}$ Dr C G Teo of the Public Health Laboratory, Colindale has identified human herpes virus 8 genome by the polymerase chain reaction amplification in the blood of $78 \%$ of patients with sarcoidosis compared with $7 \%$ in controls (personal communication).

Table 4 Site of action of immunosuppression and scope of future therapy

\begin{tabular}{ll}
\hline Immunosuppressive drug & Target \\
\hline $\begin{array}{l}\text { Corticosteroids } \\
\text { Cyclosporin }\end{array}$ & Prevent T cells producing cytokines particularly interleukin-2 \\
Tacrolimus & \\
Sirolimus (rapamycin) & Blocks intercellular signal transduction by interleukin-2 receptor \\
Azathioprine & Purine synthesis inhibitors inhibit T cell proliferation \\
Mycophenolate & Block T cell receptor \\
Monoclonal antibodies OKT3 & Block costimulatory signal CD28 \\
Cytotoxic T lymphocyte & Prevents graft $v$ host disease \\
Antigen-4-gene (CTLA-4) & Psoriasis \\
& Transplantation/Graves' disease \\
Infliximab & Human mouse chimeric antitumour necrosis factor (TNF) antibody \\
Etanercept & Human protein of recombinant p75 TNF receptors fused with Fc portion of human IgG \\
Pentoxyfylline/thalidomide & TNF blockade \\
\hline
\end{tabular}


Table 5 A correlation between genetic predisposition and clinical features (Martinetti et al $1995^{16}$ )

\begin{tabular}{lll}
\hline HLA class II & Prognosis & \\
\hline & Good & Chronic \\
A1, B8 & + & \\
DR17 & + & \\
DR3 & + & \\
DR14, DR16 & & + \\
DR5J & + & + \\
DRW52 & + & \\
DQB1 0201 & \\
DQB1 0503 & + \\
TNFA2 & \\
& Other correlations \\
DR3, DR4 & Females \\
DR5 & Males \\
B13, B35 & Early onset \\
A30, B8, DR3, DR4 & Late onset \\
B27, A2 & Pulmonary only \\
A1, B8, B27, DR3 & Stage I \\
B12, DR4 & Stage II \\
Angiotensin II type receptors & \\
$\quad$ (Takemoto et al 1998 ${ }^{17}$ ) & High activity of SACE
\end{tabular}

SACE = serum angiotensin converting enzyme.

Table 6 Suspected causal agents (Fames and Zumla $\left.1999^{5}\right)$

Bacteria and related organisms

Mycobacteria

Streptococcal cell wall

Propionibacterium acnes

Borrelia burgdorferi

Mycoplasma

Nocardia

$\begin{array}{ll}\text { Virus } & \text { Chemicals } \\ \text { Epstein-Barr } & \text { Beryllium } \\ \text { Herpes } & \text { Zirconium } \\ \text { Rubella } & \text { Pine pollen } \\ \text { Measles } & \text { Peanut dust } \\ \text { Cytomegalo } & \text { Clay } \\ \text { Coxsackie B } & \end{array}$

Retrovirus

Is sarcoidosis an autoimmune disorder?

There are several pointers to an autoimmune disorder including erythema nodosum, uveitis, sarcoid thyroiditis, Sjogren's syndrome, hypergammaglobulinaemia, the occasional presence of odd non-specific circulating antibodies, overlap syndromes with recognised autoimmune disorders; and finally an impressive response to corticosteroid therapy. However true sarcoid autoantibodies have not been regularly noted, and sarcoidosis does not share the female preponderance which is a feature of all autoimmune disorders.

1 James DG. The sarcoidosis movement and its personalities. Fournal of Medical Biography 1995;3:148-60.

2 Mishra BB, Poulter LW, Janossy G, et al. The distribution of lymphoid-and macrophage-like subsets of sarcoid and Kveim granulomata; possible mechanisms of negative PPD reactions in sarcoidosis. Clin Exp Immunol 1983;54:705-13.

3 Kawakami K, Owan I, Kaneshima H, et al. Type 1-like helper $\mathrm{T}$ cells in response to autologous peripheral blood monocytes obtained from bronchalalveolar lavage fluid and affected lymph node of patients with sarcoidosis. Sarcoidosis 1995;12:111-17.

4 Roman J, Leon YJ, Gal A, Perez RL. Distribution of extracellular matrices, matrix receptors and transforming growth factor- 1 in human and experimental granulomatous inflammation. Am f Med Sci 1995;309:124-33.

5 James DG, Zumla A, eds. The granulomatous disorders. Cambridge: Cambridge University Press, 1999.

6 Iyonaga K, Suga A, Mortitaka S, et al. Measurement of serum monocyte for estimating the activity of granuloma formation in sarcoidosis. Sarcoidosis, Vasculitis and Diffuse Lung Diseases 1998;15:165-72.

7 Kodama N, Yamaguchi E, Hizawa N. Expression of RANTES by bronchoalveolar lavage cells in non-smoking patients with interstitial lung disease. Am $\mathcal{F}$ Respir Cell Mol Biol 1998;18:526-31.

8 Hashimoto Sm, Nakayama T, Gon Y, et al. Correlation of plasma chemoattractant protein-1 (MCP1) and monocyte inflammatory protein-1 $\alpha$ levels with disease activity and clinical course of sarcoidosis. Clin Exp Immunol 1998;111: 604-10

9 Reiser H, Stadecker MJ. Costimulatory B7 molecules in the pathogenesis of infectious and autoimmune diseases. NEngl 7 Med 1996;335:1369-77.

10 Luster AD. Chemokines-chemotactic cytokines that mediate inflammation. N Engl F Med 1998;338:436-44.

11 Kumitake R, Kuwano K, Miyazaki H, et al. Apoptosis in the course of granulomatous inflammation in pulmonary sarcoidosis. Eur Respir ₹ 1999;13:1329-37.

12 Armstrong L, Foley NM, Millar AB. Inter-relationship between tumour necrosis factor alpha (TNF- $\alpha$ ) and TNF setween tumour necrosis factor alpha (TNF- $\alpha$ ) and TNF soluble rece

13 Moodley YB, Dorasamy T, Verketasamy S, et al. Correlation of CD4:CD8 ratio and tumour necrosis factor (TNF- $\alpha$ ) levels in induced sputum with bronchoalveolar lavage fluid in pulmonary sarcoidosis. Thorax 2000;55:696-9.

14 Elliott DE. The road from granuloma to fibrosis. In: James DG, Zumla A, eds. The granulomatous disorders. Cambridge: Cambridge University Press, 1999:68-78.

15 Raghu G, Johnson WC, Lockhart D, et al. Treatment of idiopathic pulmonary fibrosis with a new antifibrotic agent, idiopathic pulmonary fibrosis with a new antifibrotic agent,
pirfenidone. Am $\mathcal{F}$ Respir Crit Care Med 1999;159:1061-9.

16 Martinetti M, Tinelli C, Kolek V, et al. The sarcoidosis map. A joint survey of clinical and immunogenetic findings in two A joint survey of clinical and immunogenetic findings in two

European

17 Takemoto Y, Sakatani M, Takami S, et al. Association between angiotensin II receptor gene polymorphism and serum angiotensin converting enzyme (SACE) activity in patients with sarcoidosis. Thorax 1998;53:459-62. 